\title{
CORRECTION
}

View Article Online

View Journal I View Issue

W) Check for updates

Cite this: J. Mater. Chem. A, 2019, 7, 12900

DOI: 10.1039/c9ta90108f

www.rsc.org/MaterialsA

\section{Correction: Carbonyl-based polyimide and polyquinoneimide for potassium-ion batteries}

Bingbing Tian, ${ }^{a}$ Ji Zheng, ${ }^{\text {b }}$ Chengxi Zhao, ${ }^{\text {cf }}$ Cuibo Liu, ${ }^{a}$ Chenliang Su, ${ }^{a}$ Wei Tang, ${ }^{d}$ Xing Li $\mathrm{e}^{\mathrm{e}}$ and Guo-Hong Ning*b

Correction for 'Carbonyl-based polyimide and polyquinoneimide for potassium-ion batteries' by Bingbing Tian et al., J. Mater. Chem. A, 2019, 7, 9997-10003.

The authors regret the misspelling of the name of one of the authors (Chengxi Zhao) in the original manuscript. The corrected list of authors for this paper is as shown above.

The Royal Society of Chemistry apologises for these errors and any consequent inconvenience to authors and readers.

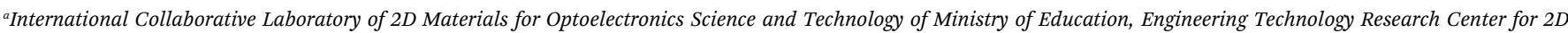

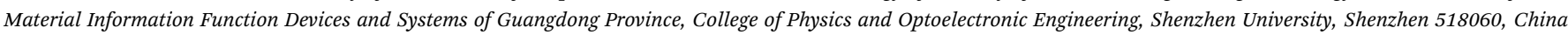
${ }^{b}$ College of Chemistry and Materials Science, Jinan University, Guangzhou, Guangdong 510632, China. E-mail: guohongning@jnu.edu.cn

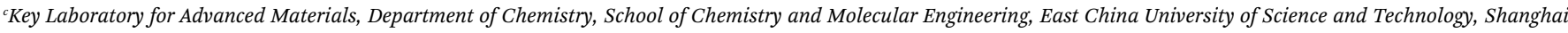
200237, China

${ }^{d}$ School of Chemical Engineering and Technology, Xi'an Jiaotong University, Xi'an, Shaanxi 710049, China

${ }^{e}$ Department of Chemistry, National University of Singapore, 3 Science Drive 3, Singapore 117543, Singapore

${ }^{f}$ Department of Chemistry and Materials Innovation Factory, University of Liverpool, Liverpool, UK
} 